\title{
Ozonation of seawater improves the survival of larval southern rock lobster, Jasus edwardsii, in culture from egg to juvenile
}

\author{
Arthur J. Ritar*, Greg G. Smith, Craig W. Thomas \\ Marine Research Laboratories, Tasmanian Aquaculture and Fisheries Institute, University \\ of Tasmania, Nubeena Crescent, Taroona, Tasmania 7053, Australia. \\ * Corresponding author. Arthur.Ritar@utas.edu.au
}

\begin{abstract}
Phyllosoma larvae of the southern rock lobster, Jasus edwardsii, were cultured from egg to juvenile. For larvae reared from hatch to Stage III, survival was highest and bacterial contamination was lowest in seawater ozonated at low and moderate levels (400 and $500 \mathrm{mV}$ oxidation-reduction potential, ORP). By contrast, at high ozonation $(600 \mathrm{mV})$, all larvae suffered deformities at the moult to Stage II and terminally starved, while in unozonated water (about $300 \mathrm{mV}$ ), all larvae died at Stage III probably as a consequence of Vibrio bacteria profileration. In a second experiment between Stages VI to VIII, larval survival was highest in ozonated water that had been filtered through activated charcoal and coral sand, compared to ozonated water with no filtration or filtered only through activated charcoal. Ozonated water with the combined filtration was used subsequently but there were ongoing deformities, so the level was progressively reduced from $400 \mathrm{mV}$ at Stage VIII to $330 \mathrm{mV}$ at Stage $\mathrm{X}$, at which time ozonation was discontinued. Larvae were then cultured in unozonated water to metamorphosis of eight pueruli at 377 to 437 days after hatch, of which two survived to juvenile. Ozonation was thus effective up to Stage IX in improving culture water to minimise bacterial disease without problems of larval deformities.
\end{abstract}

Keywords: Phyllosoma, culture, ozone, microbiology, Vibrio.

\section{Introduction}

There is great interest in Australia and internationally in the farming of rock lobsters to meet the growing demand for the highly valued product. The major limitation to its development is access to seedstock. One option is to harvest pueruli and juveniles from the wild but the capture of southern rock lobster (Jasus edwardsii) is regarded as either economically unfeasible because the yield is generally low and erratic or unsustainable because their removal may reduce recruitment to the fishery. The preferred option is to close the life cycle by culturing J. edwardsii larvae from eggs to produce commercial numbers of juvenile seedstock to be used in aquaculture. As well, there is increasing interest in enhancement of the wild fishery by reseeding with hatchery-reared juveniles.

Phyllosoma larvae of rock lobsters have a long, planktonic phase, which in $J$. edwardsii takes up to 24 months in the wild, with 11 distinct morphological stages (Lesser, 1978). For the culture of phyllosoma in the laboratory, however, the larval phase to puerulus settlement lasts approximately 12 months (Kittaka et al., 1988; Ritar and Smith, unpublished). Kittaka et al. (1988) in Japan first cultured J. edwardsii phyllosoma to the post-larval puerulus stage with one animal surviving to the juvenile stage (Kittaka et al., 2005). In Australia, J. edwardsii larvae were previously cultured to the final Stage XI before metamorphosis (Ritar, 2001) but, until this study, did not reach metamorphosis. The most success in hatchery rearing of rock lobsters has been for Panulirus japonicus where high survival rates were attributed to a novel tank design (Matsuda and Takenouchi, 2005) 
in which antibiotics were administered to reduce disease, resulting in the recent annual production of several hundreds of pueruli (H. Matsuda, personal communication).

Hatchery rearing is often plagued by sudden high mortalities preceded by fouling of the exoskeleton as well as enteritis or septicaemia, termed "white gut" syndrome (Handlinger et al., 2001). These disease states originate from the contamination with micro-organisms conveyed principally from live feeds, such as Artemia. The fouling problem appears to be associated with filamentous bacteria similar in morphology to Leucothrix mucor (Lightner, 1983) colonising and sometimes invading the exoskeleton. McAllen and Scott (2000) demonstrated that epibiont fouling organisms can affect the feeding behaviour of marine copepods, leading to inefficient prey capture or ingestion and subsequent starvation. Epibionts can also increase body density making swimming more difficult and increase contact with benthic surface biofilms resulting in further bacterial attachment. Filamentous bacteria may reduce the ability of phyllosoma to successfully complete ecdysis during this physiologically demanding period or extend the already long inter-moult phase beyond a tolerable level. The enteric disease state is associated with high numbers of Vibrio spp. bacteria (Handlinger et al., 2001). Developing techniques to reduce bacterial contamination of phyllosoma would be an important step in the successful production of juveniles.

Ozone is a powerful oxidising agent and an effective disinfectant against viral, bacterial and fungal pathogens in aquatic systems (Summerfelt and Hochheimer, 1997; Suantika et al., 2001) and has been shown to be effective in the aquaculture of crustaceans (Danald et al., 1979; Theisen et al., 1998). It is used routinely for the disinfection of eggs from various marine finfish (Arimoto et al. 1996; Battaglene and Morehead, 2006) and crustaceans (Coman et al., 2005; Sellars et al., 2005) but may be toxic to larvae (Tango and Gagnon, 2003). Marine crustaceans, though, appear tolerant to low levels of ozonation (Blogoslawski et al., 1977; Jiang et al., 2001; Meunpol et al., 2003). The external epibiont fouling organisms in early stage $J$. edwardsii phyllosoma can be controlled effectively using seawater ozonation without causing larval mortalities (Tolomei et al., unpublished data), suggesting that non-toxic levels of ozonation may be effective in the control of contaminating micro-organisms.

Buchan et al. (2003) described the most important reaction in seawater during ozonation was the initial oxidation of bromide ions $\left(\mathrm{Br}^{-}\right)$to hypobromite ions $\left(\mathrm{OBr}^{-}\right)$which can then be reduced back to $\mathrm{Br}^{-}$or further oxidised to form bromate ions $\left(\mathrm{BrO}_{3}{ }^{-}\right)$. None of these oxidised species are detectable in ambient seawater (Grguric et al., 1994). Tango and Gagnon (2003) suggested that the bromide in marine water reacts rapidly with ozone but will not form the toxic bromate as long as ammonia is present. However, as ammonia levels are low in flow-through systems, excessive bromate production could pose a potential problem to larvae in such systems. $\mathrm{OBr}^{-}$has a half-life of $<1 \mathrm{~h}$ while $\mathrm{BrO}_{3}^{-}$ appears to be stable (Richardson et al., 1981) and therefore could possibly accumulate. Bromate is classified as carcinogenic to human health by the IARC (International Agency for the Research on Cancer) and the USEPA (United States Environmental Protection Agency) and is a known toxin to fish and other aquatic life, causing respiratory and osmoregulatory dysfunction (Grguric et al., 1994). It is probably also toxic to crustaceans such as phyllosoma larvae.

A major encumbrance in the use of ozonation of seawater is that it is difficult to measure accurately the formation of ozonation by-products (OBP), particularly inorganic OBP such as bromate and other brominated compounds (Tango and Gagnon, 2003). The measurement of OBP is further complicated because the chemistry of seawater is variable especially inshore and in estuaries, often subject to fluctuations in salinity and turbidity due to wave action and terrestrial run-off. The content of OBP may be estimated indirectly 
via oxidation-reduction potential (ORP, or redox potential), which measures the potential of the seawater to oxidise or reduce, and is thus an indication of its ability to disinfect against micro-organisms or kill aquaculture animals (Tango and Gagnon, 2003). ORP may be used to control ozone addition to seawater but is not necessarily equivalent to the ability of the treated water to disinfect (Tango and Gagnon, 2003). Buchan et al. (2005) compared several methods that previously were cited regularly for determination of ozonation of seawater, suggesting that for practical hatchery purposes a DPD colourmetric method or "total chlorine test" (Franson, 1976) be used, and that results be reported as total residual oxidants in terms of $\mathrm{mg} \mathrm{Cl}_{2} \mathrm{l}^{-1}$. A more direct measure of bromide and bromate level includes colorimetric methods (Clesceri et al., 1989, cited by Liltved et al., 1995; Tango and Gagnon, 2003). However, Buchan et al. (2005) emphasised that an accurate method that is easy to administer still needs to be developed. Further, these direct measures are more insensitive to low levels of OBP compared to ORP levels.

We suspect that there are low levels of inorganic OBP that are safe for use during larval rearing of lobster phyllosoma, and probably other crustaceans, and have considerable disinfective properties. This would be advantageous and avoid the need for antibiotics, which are generally considered undesirable for aquaculture. Our preliminary investigation (unpublished) indicated that ozonation of seawater could be applied to the flow-through culture of phyllosoma to improve larval survival by reducing the presence of pathogens associated with live feeds.

This study examined different levels of ozonation of culture water, as determined by ORP levels, on the survival, growth and bacteriology of phyllosoma through to Stage III of development. Ozonation was subsequently used in the more sensitive later larval stages. The study also reports on the successful culture of J. edwardsii phyllosoma through to metamorphosis at the puerulus stage and then on to juveniles.

\section{Materials and Methods}

\section{Experimental animals}

Newly-hatched phyllosoma were collected from a female weighing approximately 1 $\mathrm{kg}$ and held in captivity in a 4,000 1 tank under a regime of ambient temperature and photoperiod as described by Smith et al. (2003a) at the Tasmanian Aquaculture and Fisheries Institute, Marine Research Laboratories (TAFI MRL), Hobart. Larval viability at hatch was high as assessed by an activity test (Smith et al. 2003b) which measured the rate of loss in vitality during a one-hour period at low salinity $(10 \%)$ and elevated water temperature $\left(21^{\circ} \mathrm{C}\right)$ and is directly related to the survival of phyllosoma during culture.

\section{Water treatment and ozonation}

Seawater pumped from the Derwent River estuary was filtered to $1 \mu \mathrm{m}$, foamfractionated, disinfected with ultra-violet irradiation before passing through activated carbon and heated to $18^{\circ} \mathrm{C}$, and was termed unozonated water. The production of ozonated water entailed the injection of ozone into unozonated water through an airstone to an ORP of $750 \mathrm{mV}$, measured using a Pinpoint ORP Monitor (American Marine Inc., Ridgefield, CT, USA) in a 3001 enclosed ozonation sump with a water turnover of about $1,5001 \mathrm{~h}^{-1}$. Ozone was produced by an OZ1BTUS ozone generator $(5.1 \mathrm{~g} / \mathrm{h}$; Ozotech Inc., Yreka, CA, USA) supplied with oxygen from a Millennium M5 concentrator (Respironics, Kennesaw, GA, USA). 


\section{Larval culture}

The system for culture of phyllosoma was described previously (Ritar, 2001). Briefly, the water entering circular plastic tanks with a 101 capacity was jetted through four equally-spaced nozzles positioned near the bottom perimeter of the tanks and another two nozzles towards the bottom centre of the tanks to provide a circular flow to assist phyllosoma movement through the water column. The single pass of water flow to each tank was adjusted to at least $600 \mathrm{ml} \mathrm{min}^{-1}$ and the volume was maintained at a constant 101 with excess water exiting through a screen positioned on the wall of the tank. Tanks were changed approximately every two weeks and phyllosoma were transferred to clean tanks (by pouring) after uneaten food and debris were removed from the dirty tanks.

\section{Experiment 1: Level of ozonation for the culture of larvae from Stage I to III}

Four treatments, each with four replicates, consisted of:

1. No ozone $(300 \mathrm{mV})$ - unozonated water with a target ORP of $300 \mathrm{mV}$ although this varied depending on water quality. For example, lower ORP levels of the intake water occurred with high rainfall that reduced the salinity and was probably accompanied by run-off contamination from land surrounding the estuary.

2. Low ozone $(400 \mathrm{mV})$ - had an ORP of $400 \mathrm{mV}$ achieved by mixing unozonated water in treatment 1 with water ozonated to $750 \mathrm{mV}$.

3. Medium ozone $(500 \mathrm{mV})$ - as for treatment 2 except that the mixed water had an ORP of $500 \mathrm{mV}$.

4. High ozone $(600 \mathrm{mV})$ - as for treatment 2 except that the mixed water had an ORP of $600 \mathrm{mV}$.

The required ORP levels for the mixes of unozonated and ozonated water were monitored with probes positioned constantly in separate culture tanks with only clear water and no phyllosoma or Artemia (ORP levels tended to be lower by up to $50 \mathrm{mV}$ in culture tanks with phyllosoma plus Artemia) and adjusted twice daily or as required.

Stage I phyllosoma were stocked at hatch at a rate of $30 \mathrm{l}^{-1}\left(300 \mathrm{tank}^{-1}\right)$ and fed a daily ration of 1.5-2.0 mm long Artemia at a density of 1.5 Artemia $\mathrm{ml}^{-1}$. Artemia remaining from the previous day's ration were flushed from the culture tanks for $4 \mathrm{~h}$ prior to feeding the next daily ration of recently prepared Artemia.

Experiment 2: Treatment of ozonated water for the culture of larvae from Stage VI to VIII

This experiment used larvae which had been raised in mass-rearing tanks (50 1 conical upwellers) to Stage III and then on-grown in circular plastic tanks (see above) to Stage VI in ozonated seawater (ORP $390-440 \mathrm{mV}$ ) as described in Experiment 1. The experiment examined filtration treatments to reduce the ORP of ozonated water before entering the culture tanks. It commenced with 420 phyllosoma at Stage VI and 64 days after hatch. Each treatment contained four replicate tanks of approximately 35 larvae and compared:

1. Ozonated water - with ORP of 450-500 $\mathrm{mV}$ achieved by mixing unozonated water with water ozonated to $750 \mathrm{mV}$.

2. Ozonated water from treatment 1 passed through activated charcoal (Reef Carbon, Aquasonic, Australia) resulting in an ORP of $400-450 \mathrm{mV}$.

3. Ozonated water from treatment 1 passed through activated charcoal and coral sand (broken coral) resulting in an ORP of 390-440 mV.

The charcoal and coral sand were each compacted into separate enclosed cylinders of approximately 41 volume with the ozonated water entering the top of the cylinder, passing through the media before exiting from the bottom. 
In addition to the daily feed of Artemia as in Experiment 1, mussel pieces (1-2 mm diameter) were disinfected in $100 \mathrm{ppm}$ sodium hypochlorite for $30 \mathrm{~min}$, rinsed in clean water and fed daily.

\section{Culture of larvae from Stage VIII to metamorphosis as puerulus and beyond to juvenile} stage

At 126 days after hatch when 150 phyllosoma were at Stage VIII, daily feeding of 1.5$2.0 \mathrm{ml}$ Artemia was changed to feeding only every 2-3 days with large juvenile and adult Artemia ( $\geq 6 \mathrm{~mm}$ and mostly $\geq 10 \mathrm{~mm}$ ). Larvae continued to receive mussels but the whole gonads had been disinfected for only 10 min before rinsing and chopping into $2 \mathrm{~mm}$ pieces. Initially, there were approximately 20 larvae per culture tank but, as larvae grew, this density was reduced either by natural attrition or by moving to other culture tanks. The level of ozonation and other husbandry practices were manipulated as described in Results below.

\section{Artemia production}

Artemia cysts (AAA grade, Artemia Systems, INVE, Belgium) were hatched in 501 conical tanks at $28^{\circ} \mathrm{C}$ in $1 \mu \mathrm{m}$-filtered ozonated seawater with vigorous aeration and a 150 $\mathrm{W}$ incandescent light suspended $0.5 \mathrm{~m}$ above the water surface. Hatched nauplii were rinsed for $5 \mathrm{~min}$ and stocked in 6701 tanks at 5 Artemia $\mathrm{ml}^{-1}$ before on-growing to 1.5-2.0 $\mathrm{mm}$ (for larvae up to Stage VIII) or $\geq 6 \mathrm{~mm}$ (Stage VIII onwards to metamorphosis) in flow-through tanks receiving a diet of blended brine shrimp food (consisting of rice pollard, soyflour and wheat flour; Eyre Peninsula Aquafeeds Pty Ltd, South Australia) and algae (T. Isochrysis and Chaetoceros muelleri). Prior to feeding to phyllosoma, Artemia were disinfected by purging in dense C. muelleri $\left(10^{7}\right.$ cells $\left.\mathrm{ml}^{-1}\right)$ as described by Tolomei et al. (2004) and $400 \mathrm{ppm}$ formalin for $60 \mathrm{~min}$ before rinsing and feeding to culture tanks.

\section{Determination of moults, mortalities and larval size}

In experiment 1, larval exuviae and mortalities were removed and counted daily. Mortalities were confirmed by counting all survivors 3-5 days after the moult to Stages II and III i.e. on Days 14 and 26 after the hatch. At hatch and on Days 14 and 26, a sample of larvae $(n=15)$ from each culture tank was measured for body length (from the anterior tip of the cephalic shield between the eyestalks to the posterior tip of the abdomen) on a profile projector (Nikon 6C, Japan) before returning to culture tanks. After Stage III, larvae were counted and measured at regular intervals, within 5-8 days after the estimated peak of moult. In Experiment 2, larvae moulted to Stages VII and VIII (first instar) at approximately Days 70 and 85 after hatch, respectively, which is in accordance with a previous report on moulting patterns (Ritar, 2001), and survivals were assessed approximately 10 days after the peak of moulting.

\section{Bacteriology}

In Experiment 1, triplicate samples of water and phyllosoma were collected on Day 0 before newly-hatched larvae were stocked into culture tanks and then from replicate tanks in each treatment on Day 5 (during Stage I), Day 12 (shortly after moult to Stage II) and Day 21 (shortly after moult to Stage III) to determine the bacterial content. Artemia were also sampled on Days 4, 11 and 20 immediately after purging (but before entry to phyllosoma tanks) and after they had been in culture tanks for $21 \mathrm{~h}$. Phyllosoma and Artemia samples were homogenised (sterile Bel-Art ${ }^{\circledR}$ pestle) in sterile $1.5 \mathrm{ml}$ microfuge tubes, serially diluted $\left(10^{-1}, 10^{-2}, 10^{-3}\right.$ and $\left.10^{-4}\right)$ and spread plated onto marine agar and thiosulphate citrate bile salts (TCBS) agar (Amyl Media AM243 and AM187, respectively, 
Australia) for the measurement of total aerobic marine heterotrophic bacteria and Vibrio spp. After incubation for $24 \mathrm{~h}$ at $20-25^{\circ} \mathrm{C}$, plates containing between 30 and 300 colony forming units were selected and enumerated. Internal phyllosoma bacteriology was similarly assessed after disinfecting the external surfaces by immersing larvae in $0.1 \%$ benzalkonium chloride (i.e. 10\% stock solution from APEX Labs mixed 1 in 100 with sterile seawater) for $1 \mathrm{~min}$ and washing under running seawater for $30 \mathrm{~s}$ (modified from Muroga et al. 1987).

\section{Statistical analyses}

Statistical analyses were performed using JMP version 5.0 (SAS Institute Inc.) for one-way ANOVA and Tukey-Kramer HSD tests for post-hoc multiple comparisons (Sokal and Rohlf, 1995). After arcsin $\sqrt{ }$ transformations were performed, survival data were normal and homogeneous. The level of significance for all analyses was $\mathrm{P}<0.05$. Data are presented as mean \pm standard error unless stated otherwise.

\section{Results}

Experiment 1: Level of ozonation for the culture of larvae from Stage I to III Phyllosoma survival and size

The survival of phyllosoma larvae to Day 26 in the four ozonation treatments was significantly different $(\mathrm{P}<0.05$, Fig. 1). Larvae receiving No Ozone had a survival of $68 \%$ to Day 14 but all died by Day 26. Larvae in Low and Medium Ozone had survivals to day 14 of $81 \%$ and $71 \%$, respectively, and to Day 26 of $55 \%$ and $64 \%$, respectively. Larvae in the No Ozone, Low and Medium Ozone were morphologically normal but those in the High Ozone treatment did not complete the moult to Stage II, suffering an abnormal naupliosoma-like appearance showing deformed limbs, carapaces and eyes (Fig. 2), preventing them from progressing to Stage II and from feeding until their death at approximately Day 18 post-hatch. The total body length of surviving larvae was not significantly different between treatments and overall was $2.02 \pm 0.11 \mathrm{~mm}$ at Stage I, 3.02 $\pm 0.20 \mathrm{~mm}$ at Stage II, and $4.06 \pm 0.37 \mathrm{~mm}$ at Stage III.

\section{Microbiology of culture water, Artemia and phyllosoma}

There were highly significant differences in bacterial content of Artemia before feeding to phyllosoma on Days 5, 12 and 21 (Fig. 3a). On Days 5 and 21, numbers of Vibrio spp. $\left(1.4 \times 10^{3}\right.$ and $\left.1.4 \times 10^{2}\right)$ per Artemia and total heterotrophic bacteria $\left(8.1 \times 10^{3}\right.$ and $2.3 \times 10^{2}$ ) per Artemia were elevated compared to those on Day 12 (no Vibrios, 42 total bacteria). Subsequently, after $21 \mathrm{~h}$ in culture on Days 5 and 21, the total bacteria and number of Vibrio per Artemia were similar or lower for all treatments compared to Artemia before entering phyllosoma culture tanks. In contrast, at Day 12, Artemia had higher Vibrio content, but similar total bacteria, after $21 \mathrm{~h}$ in culture. This pattern of number of Vibrio and total bacteria in Artemia after $21 \mathrm{~h}$ in culture was reflected in bacterial content of the culture water (Fig. 3b).

For the combined (internal plus external) bacteria in phyllosoma on Day 5, total heterotrophs were similarly elevated for all treatments, whereas there were no Vibrio for the Medium and High treatments compared to No ozone $\left(3.3 \times 10^{2}\right)$ and Low ozone $(1.7 \mathrm{x}$ $10^{3}$ ) treatments (Fig. 4). On Day 12, Vibrio bacteria were absent in all the ozone treatments and only present in the No Ozone treatment $\left(1.5 \times 10^{2}\right)$, while the numbers of total bacteria progressively reduced as the ozonation level increased. On Day 21 for the No Ozone treatment, just prior to the complete mortality of all phyllosoma, all bacteria $\left(>1.3 \times 10^{5}\right)$ 
were Vibrios, whereas there were no Vibrios in the Low treatment and 51 in the Medium treatment.

When internal bacterial numbers were examined on Day 12, only 17 total heterotrophs were found in the Low treatment, while no bacteria were found in the other treatments (Fig. 4b). On Day 21, internal bacterial content reflected the combined content albeit at a 10 -fold lower level, with $2.8 \times 10^{3}$ Vibrio and $3.9 \times 10^{3}$ total bacteria for the No Ozone treatment and 14 Vibrio and 88 total bacteria for the Medium treatment. Interestingly, the highest survival in one culture tank occurring in the Medium treatment was associated with some Vibrio content which was isolated as a possible future probiont.

Experiment 2: Treatment of ozonated water for the culture of larvae from Stage VI to VIII

In Experiment 2, there was a decline in phyllosoma survival across all treatments (Fig. 5). For ozonated water alone, survival at Stages VII and VIII was $32 \%$ and $20 \%$, respectively, while for ozonated water with charcoal, survival was $44 \%$ and $33 \%$, respectively. Mortalities in these treatments were primarily associated with deformities at the moults as seen previously in the first experiment in the high ozonation treatment. By contrast, survival was highest in ozonated water with activated charcoal and coral sand, remaining at $76 \%$ and $70 \%$ at Stages VII and VIII, respectively, with mortalities mainly due to previous exposure to high ozonation before the commencement of the experiment.

\section{Culture of larvae from Stage VIII to metamorphosis as puerulus and beyond to juvenile stage}

The 112 Stage VIII phyllosoma remaining after Experiment 2 developed increasing sensitivity to the level of ozonation in seawater (treated with charcoal and coral sand), which at 172 days after hatch was 400-450 mV ORP. The survival and growth to metamorphosis is illustrated in Fig. 6 for measurements taken on Days 172, 228, 291 and 361 (intermediate measurements also taken on Days 200, 256 and 333). Between Days 173-186, deaths occurred apparently due to bacterial contamination via the Artemia. Subsequently, phyllosoma developed increasing sensitivity to ozonation. A spike in ORP $(550 \mathrm{mV})$ on Day 208 induced fatal deformities at the moult in some animals, as did a spike on Day $216(460 \mathrm{mV})$. Ozonation was thus reduced to $380-440 \mathrm{mV}$. Further deformities occurred on Day 229 at $430 \mathrm{mV}$ and ozonation was reduced to $360-400 \mathrm{mV}$. Deformities were again noted on Day 245 and ozonation was reduced to 330-350 mV. On Day 250 at Stage X, new deformities occurred, so three of the five tanks received only unozonated water. The remaining two tanks continued to receive ozonated water for $3 \mathrm{~h}$ in the afternoons, outside their normal moulting period around dawn, but this was only successful for one week when phyllosoma moulting later in the mornings were again compromised by ozonation. Therefore, ozonation was discontinued in all tanks. No further deformities were evident when only unozonated water was used for larval culture and phyllosoma deaths were caused primarily due to mechanical damage consisting of larger animals entangling on tank screens and fittings. To remedy this, fittings were modified to fill crevices while screens were repositioned.

As examples of the wide distribution in stages (and sizes) late in larval development, on Day 291 there were 6, 54 and 7 phyllosoma at Stages VIII, IX and X, respectively, while on Day 361, there were 3, 23 and 13 phyllosoma at Stages IX, X and XI, respectively.

There were eight larvae that metamorphosed to the puerulus stage and the culture time from hatch was 377 to 437 days. Two pueruli survived and moulted to the post-puerulus stage at 19 and 21 days after metamorphosis and survived as juveniles. Animals did not eat when presented with Artemia and chopped mussel at the puerulus stage but ate 
immediately after moulting to post-puerulus. A pelleted diet (Vital Prawn, Higashimaru, Japan; containing $66 \%$ protein and $12 \%$ lipid) was introduced when juveniles were 3 months old, and chopped mussel was replaced with whole mussel gonad at 6 months old when Artemia were withdrawn. At 12 months, pueruli had moulted 10 times since metamorphosis and were $16 \mathrm{~g}$ and $32 \mathrm{~g}$ (male and female).

\section{Discussion}

A paramount factor in the successful rearing of phyllosoma larvae from hatch through to Stage IX was the adoption of ozonation to disinfect culture water, whereas subsequent stages could not tolerate ozonated water. Long-term culture of larval crustaceans in ozonated seawater is a new field, requiring innovative technologies. The highly active OBP kill bacteria and oxidise organics and inorganics to inactive forms. In finfish and shellfish hatcheries, these OBP are typically stripped from the system using a variety of techniques including ozone destruction chambers, ultra-violet irradiation and activated charcoal filtration, thus providing clean, disinfected water safe for larval rearing. However, as the large majority of bacterial contamination in phyllosoma culture enters via the food vector Artemia, this application of ozone would only have a partial benefit. Instead, phyllosoma have some resistance to OBP thus providing an opportunity to reduce bacterial contamination in culture by maintaining a background level of OBP in the water.

OBP's at low concentrations are difficult to measure in seawater. Therefore, to provide an indirect indication of the ability of the water to degrade bacteria, the ORP was measured as an estimate of the OBP concentration available in the water. Water with a high ORP has a greater capacity to oxidise material in the water column, including suspended solids, bacteria and even phyllosoma when too high. There should be an awareness that, as Liltved et al. (1995) highlighted, there is a problem with estimating ozonation using ORP (redox potential), especially under varying water quality conditions, as well as the difficulties in using it to predict bacterial inactivation. In this study, however, where water quality was constant to all experimental treatments, the indirect measure of ORP was satisfactory, regardless of the problem noted by Katzenelson et al. (1974, as cited by Liltved et al., 1995) that redox potential increases rapidly with increasing ozone concentration from 0.03 to $0.20 \mathrm{ppm}$, but at higher concentrations it levels off sharply.

High larval mortality in unozonated water is typical of phyllosoma culture where opportunistic proliferation of gut pathogens, mainly Vibrio spp., and epibiont microorganisms may result in rapid death of phyllosoma in some or all culture tanks. In fact, larval survival between culture tanks is typically variable; mortalities are even low occasionally when pathogen levels remain low (Ritar et al., 2002). In Experiment 1, the bacterial content of the phyllosoma appeared to be a more accurate reflection of their health than the bacterial content of Artemia or culture water. For unozonated water on Day 21, only 1-2 days after the moult to Stage III, the number of Vibrio bacteria had reached $10^{5}$ phyllosoma ${ }^{-1}$ followed by complete mortality in all larvae within the next 5 days, suggesting that mortalities were a consequence of Vibrio proliferation. By contrast, larval survivals remained $>60 \%$ in treatments receiving low or medium ozonation and in both cases there were low levels of detectable bacteria. This clearly indicates that ozonation suppresses bacterial proloferation and confirms earlier findings that gram-negative bacteria, such as Vibrio spp., are especially sensitive to ozonation (Restaino et al., 1995).

The internal bacterial content of phyllosoma appeared to reflect the whole (internal plus external) content but was some 10- to 100 -fold lower, suggesting that most bacteria reside on external surfaces and comparatively few internally. However, the data collected were limited and the method for assessing internal bacterial content, as modified from 
Muroga et al., (1987), whereby the animals are briefly rinsed in a weak solution of benzalkonium chloride, needs to be further validated for phyllosoma to support this contention.

Vibrio and total heterotrophic bacterial content of Artemia were reduced by up to $97 \%$, down to $10^{3}$ bacteria Artemia $^{-1}$, when stomach contents were purged for as little as $45 \mathrm{~min}$ in a dense culture $\left(10^{7}\right.$ cells ml $\left.{ }^{-1}\right)$ of the alga C. muelleri (Tolomei et al., 2004). Further reductions occurred when formalin at a concentration of 100-400 ppm was included in the algal purge (Ritar, Smith and Thomas, unpublished data). In Experiment 1, the numbers of Vibrio bacteria Artemia ${ }^{-1}$ immediately after the algal and formalin purge ranged from 0 to $10^{3}$ on the different sampling dates and were closely associated with total heterotrophic bacteria which ranged from $10^{2}$ to $10^{4}$. This indicates that, although purging is effective in reducing Artemia bacterial content, some pathogens remained and may have proliferated in culture to colonise the hepatopancreas and other organs of the larvae when ingested. There was also considerable day-to-day variability in the number of bacteria, particularly Vibrio spp., introduced to the culture tanks via the Artemia. In most cases, Artemia bacterial content was reduced somewhat over the $24 \mathrm{~h}$ they remained in the larval culture tanks, especially at the higher levels of ozonation, and this pattern was reflected in the bacterial content of the culture water. However, the bacterial content of phyllosoma more accurately reflected or predicted phyllosoma health than the bacterial content of Artemia and culture water.

It is thus likely that the beneficial anti-bacterial effects of ozonation are most directly at the level of the phyllosoma, possibly during digestion of the Artemia. The presence of OBP's within the hepatopancreas may have reduced the pathogenic Vibrio content to minimise the opportunity for the development of disease. Although not examined in this study, it is likely that the epibiont fouling was also reduced by ozonation as found previously by Tolomei et al. (unpublished data).

A key finding of this study is that excessive ozonation induces abnormalities at the moult in phyllosoma which are most sensitive during later larval stages of development. This problem of abnormalities has not been described previously in any other crustacean. The deformed larvae were trapped irreversibly during the moult to Stage II at Day 9-11 after hatch and died by Day 18 . This was possibly from starvation although our earlier study found that continuous starvation at either Stage II or Stage IV resulted in larvae surviving for at least an additional 12-18 days beyond the next expected moult (Ritar et al., 2003). The affected larvae hardened into deformed shapes, mostly with eyes, legs, the lower thorax and even the cephalic shield partly or fully rounded, which hindered or prevented them from swimming and eating compared to the normal, almost twodimensional larvae. Similar deformities were seen at later stages of development at lower levels of ozonation and were generally fatal and irreversible except where abnormalities were mild. Larvae appeared to be most sensitive to excess ozonation within approximately $24 \mathrm{~h}$ of commencing to moult, while at other times, larvae could withstand high levels of ozonation with no noticeable long-lasting adverse effects.

The deformities may occur as a direct result of some OBP's, such as bromine and bromate, disrupting the normal moulting physiology. In marine finfish, OBP's caused abnormalities, probably due to alterations in the enzymatic processes, in the egg chorion and delayed hatching (Arimoto et al., 1996; Mimura et al., 1999; Grotmol and Totland, 2000; Battaglene and Morehead, 2006). Fukunaga et al. (1992) found that ozone exposure decreased activities of oxygen scavenging enzymes by up to $80 \%$ in the tissue of Japanese charr Salvelinus leucomaenis. In mammals, ozone-induced reactive oxygen species are capable of causing oxidative stress which is reflected in peroxidation of lipids, loss of functional groups and enzyme activities and alteration in membrane permeability (Mustafa, 
1990). Also in fish, exposure to brominated organics may cause degenerative changes in superficial epithelia of the gills and oral mucosa (Wester et al., 1988). Clearly, if ozonation is to be used for the culture of crustacean larvae, further investigations are required on its effects on moulting.

The high survival and low incidence of deformities in larvae cultured in ozonated water after filtration through activated charcoal and coral sand (390-440 mV) suggests that there are some components that are absorbed by the two media that are harmful to larval development compared to ozonated water with no treatment $(450-500 \mathrm{mV})$ or ozonated water treated only with activated charcoal $(400-450 \mathrm{mV})$. Coral sand is constituted mainly of calcium carbonate which is used by crustaceans in the moulting process (Wheatly, 1999). Thus, this medium may provide constant release of calcium carbonate into the water supply for larval culture. Activated charcoal adsorbs numerous contaminants, particularly organic impurities, from aqueous solutions, thereby enhancing water quality. On the other hand, the combined activated charcoal and coral sand may simply improve survival by reducing the oxidative capacity of the water, which in turn may suffice to allow moulting to continue unhindered. In any case, activated charcoal and coral sand were used successfully for the culture to subsequent stages of larval development.

From Stage VIII, the level of ozonation was progressively reduced from 400-450 mV to the point where it was terminated and only unozonated water $(\sim 300 \mathrm{mV})$ was used for culture at Stage $\mathrm{X}$ some 250 days after hatch. This suggests that later stages of larval development are more sensitive to ozonation, which was supported by our experience in the following year with another batch of phyllosoma. During this period, the occasional occurrence of a surge or spike of ozonation, resulting in a sudden elevation of ORP to 460$550 \mathrm{mV}$, immediately lead to further deformities and death of some larvae at the moult. This heightened sensitivity to OBP coincided with the first appearance of external gills buds (Lesser, 1978). An attempt to briefly introduce ozonated water for only $3 \mathrm{~h}$ daily in the afternoons, outside the putative moulting period, still resulted in deformities because, unlike some other lobster species where moulting occurs consistently around dawn (Mikami and Greenwood, 1997), J. edwardsii phyllosoma may moult at other times and are not noted for close synchrony associated with photoperiod (Ritar and Smith, unpublished data). Even though phyllosoma become more sensitive to the adverse effects of ozonation at later stages of development, it appears that they become more resistant to microbial infection and contamination.

In addition to the benefits of ozonation to reduce bacterial contamination in phyllosoma, other factors were important in improving survival during larval culture. The ambient light intensity for rearing was reduced by 100 -fold (to $0.05-0.1 \mu \mathrm{mol}^{-1} \mathrm{~m}^{-2}$ ) resulting in phyllosoma feeding more actively. Mussels were disinfected in $100 \mathrm{ppm}$ sodium hypochlorite for $10 \mathrm{~min}$ instead of $30 \mathrm{~min}$, improving palatability. Instead of feeding small (1.5-2.0 mm) Artemia, phyllosoma after Stage VIII were fed Artemia at least $6 \mathrm{~mm}$ long, and mostly $\geq 10 \mathrm{~mm}$. Water flow and turbulence in the tanks were increased, stimulating greater movement in final stage phyllosoma and at metamorphosis. 


\section{Conclusion}

The culture of phyllosoma to Stage IX using ozonated seawater was effective in controlling pathogenic bacteria to improve larval survival. However, excessive ozonation caused deformities and eventual death. Tolerance to ozonation declined at later stages of larval development. It is clear that ozonation needs to be monitored and controlled precisely to deliver an effective disinfection for the benefit of larval health while avoiding the detrimental toxins causing deformities and death. Thus, a better understanding is needed of the changes in water chemistry during ozonation and improved technologies are required to accurately measure the levels of OBP in ozonated seawater.

\section{Acknowledgements}

This research was funded by the Fisheries Research and Development Corporation, Rock Lobster Enhancement and Aquaculture Subprogram: Propagation of southern rock lobster (Jasus edwardsii) in Tasmania (project number 2003/212). We thank Professor Jiro Kittaka and Dr Hirokazu Matsuda for their very helpful advice on larval rearing, Mr Bill Wilkinson for the production of live feeds and the aquaculture staff for invaluable assistance.

\section{References}

Arimoto, M., Sato, J., Maruyama, K., Mimura, G., Furusawa, I. 1996. Effect of chemical and physical treatments on the inactivation of striped jack nervous necrosis virus (SJNNV). Aquaculture 143, 15-22.

Battaglene, S.C., Morehead, D.T. 2006. Tolerance of striped trumpeter Latris lineata eggs to ozonated seawater. Aquaculture International (in press).

Blogoslawski, W., Brown, C., Lewis, D., Leong, J. 1977. Use of ozone for crustacean disease prevention: a brief review. Proceedings of the Second Biennial Crustacean Health Workshop, Galveston, TX, USA, pp. 220-230.

Buchan, K.A.H., Martin-Robichaud, D.J., Benfey, T.J. 2005. Measurement of dissolved ozone in sea water: a comparison of methods. Aquacultural Engineering 33, 225-231.

Coman, G.J., Sellars, M.J., Morehead, D.T. 2005. Toxicity of ozone generated from different combinations of ozone concentration $(C)$ and exposure time $(T)$ : a comparison of the relative effect of $C$ and $T$ on hatch rates of Penaeus (Marsupenaeus) japonicus. Aquaculture 244, 141-145.

Danald, D., Ure, J., Lightner, D. 1979. Preliminary results of ozone disinfection of seawater containing the potential shrimp pathogens Vibrio sp. and Fusarium solani. Ozone: Science and Engineering 1, 329-334.

Franson, M.A. 1976. DPD colormetric method. Standard Methods for the Examination of Water and Wastewater. $14^{\text {th }}$ ed. American Public Health Association, Washington, DC. pp. 332-334.

Fukunaga, K., Suzuki, T., Hara, A., Takama, K. 1992. Effect of ozone on the activites of reactive oxygen scavenging enzymes in RBC of ozone exposed Japanese charr Salvelinus leucomaenis. Free Radical Research Communications 17, 327-333.

Grguric, G., Trefry, J.H., Keaffaber, J.J. 1994. Ozonation products of bromine and chlorine in seawater aquaria. Water Research 28, 1087-1094.

Grotmol, S., Totland, G.K. 2000. Surface disinfection of Atlantic halibut Hippoglossus hippoglossus eggs with ozonated sea-water inactivates nodavirus and increases survival of the larvae. Diseases of Aquatic Organisms 39, 89-96. 
Handlinger, J.H, Carson, J., Ritar, A.J., Crear, B.J., Taylor, D.P., Johnson, D.J. 2001. Disease conditions of cultured phyllosoma larvae and juveniles of the southern rock lobster (Jasus edwardsii, Decapoda; Palinuridae). Ed.s Evans, L.H. and Jones, J.B. In: Proceedings of the International Symposium on Lobster Health Management, (Ed. L.H. Evans and J.B. Jones), pp. 75-87. Curtin University Publication. CD-ROM and website (http://www.curtin.edu.au/curtin/muresk/lhm/index.htm).

Jiang, G., Liu, Y., Yang, D., Lu, Y. 2001. The toxicity of ozonated seawater to the Penaeus chinensis and Paralichthys olivaceus. Marine Science 25, 11-13.

Kittaka, J., Iwai, M., Yoshimura, M. 1988. Culture of a hybrid of spiny lobster genus Jasus from egg stage to puerulus. Nippon Suisan Gakkaishi 54, 413-417.

Kittaka, J., Ono, K., Booth, J.D., Webber, W.R. 2005. Development of the red rock lobster, Jasus edwardsii, from egg to juvenile. New Zealand Journal of Marine and Freshwater Research 39, 263-277.

Lesser, J.H.R. 1978. Phyllosoma larvae of Jasus edwardsii (Hutton) (Crustacea: Decapoda: Palinuridae) and their distribution off the east coast of the North Island, New Zealand. New Zealand Journal of Marine and Freshwater Research 12, 357-370.

Lightner, D. 1983. Diseases of cultured penaeid shrimp. In: McVey, J.P. (Ed.), CRC Handbook Mariculture Volume 1 Crustacean Aquaculture. CRC Press Inc., Boca Raton, pp. 289-320.

Liltved, H., Hektoen, H., Efraimsen, H. 1995. Inactivation of bacterial and viral fish pathogens by ozonation or UV irradiation in water of different salinity. Aquacultural Engineering 14, 107-122.

McAllen, R., Scott, G.W. 2000. Behavioural effects of biofouling in marine copepods. Journal of the Marine Biological Association (United Kingdom) 80, 369-370.

Matsuda, H., Takenouchi, T. 2005. New tank design for larval culture of Japanese spiny lobster, Panulirus japonicus. New Zealand Journal of Marine and Freshwater Research 39, 279-285.

Meunpol, O., Lopinyosiri, K., Menasveta, P. 2003. The effects of ozone and probiotics on the survival of black tiger shrimp (Penaeus monodon). Aquaculture 220, 437-448.

Mikami, S., Greenwood, J.G. 1997. Influence of light regimes on phyllosomal growth and timing of moulting in Thenus orientalis (Lund) (Decapoda: Scyllaridae). Marine and Freshwater Research 48, 777-782.

Mimura, G., Nagase, T., Katayama, Y., Namba, K. 1999. Physiological and histological observation of delayed hatching of eggs. Nippon Suisan Gakkaishi 65, 448-456.

Muroga, K., Higashi, M., Keitoku, H. 1987. The isolation of intestinal microflora of farmed red seabream (Pagrus major) and black seabream (Acanthopagrus schlegeli) at larval and juvenile stages. Aquaculture 65, 79-88.

Mustafa, M.G. 1990. Biochemical basis of ozone toxicity. Free Radical Biology and Medicine 9, 245-260.

Restaino, L., Frampton, E.W., Hemphill, J.B., Palnikar, P. 1995. Efficacy of ozonated water against various food-related microorganisms. Applied and Environmental Microbiology 61, 3471-3475.

Richardson, L. B., Burton, D.T., Helz, G.R., Rhoderick, J.C. 1981. Residual oxidant decay and bromate formation in chlorinated and ozonated sea-water. Water Research 15, 1067-1074.

Ritar, A.J. 2001. The experimental culture of phyllosoma larvae of southern rock lobster (Jasus edwardsii) in a flow-through system. Aquacultural Engineering 24, 149-156.

Ritar, A.J. Thomas, C.W., Beech, A.R. 2002. Feeding Artemia and shellfish to phyllosoma larvae of southern rock lobster (Jasus edwardsii). Aquaculture 212, 183-194. 
Ritar, A.J., Dunstan, G.A., Crear, B.J., Brown, M.R. 2003. Biochemical composition during growth and starvation of early larval stages of cultured spiny lobster (Jasus edwardsii) phyllosoma. Comparative Biochemistry and Physiology Part A 136, 353370.

Sellars, M.J., Coman, G.J., Morehead, D.T. 2005. Tolerance of Penaeus (Marsupenaeus) japonicus embryos to ozone disinfection. Aquaculture 245, 111-119.

Smith, E.G., Ritar, A.J., Carter, C.G., Dunstan, G.A., Brown, M.R. 2003a. Morphological and biochemical characteristics of phyllosoma after photothermal manipulation of reproduction in broodstock of the spiny lobster, Jasus edwardsii. Aquaculture 220, 299-311.

Smith, G.G., Ritar, A.J., Dunstan, G.A. 2003b. An activity test to evaluate larval competency in spiny lobsters (Jasus edwardsii) from wild and captive ovigerous broodstock held under different environmental conditions. Aquaculture 218, 293-307.

Sokal R.R. \& Rohlf J.F. 1995. Biometry: The principles and practice of statistics in biological research. Freeman. New York, 468p.

Suantika, G., Dhert, P., Rombaut, G., Vandenberghe, J., De Wolf, T., Sorgeloos, P. 2001. The use of ozone in a high density recirculation system for rotifers. Aquaculture 201, $35-49$.

Summerfelt, S.T., Hochheimer, J.N. 1997. Review of ozone processes and applications as an oxidising agent in aquaculture. Progressive Fish Culturist 59, 94-105.

Tango, M. S., Gagnon, G.A. 2003. Impact of ozonation on water quality in marine recirculation systems. Aquacultural Engineering 29, 125-137.

Thiesen, D., Stansell, D., Woods, L. 1998. Disinfection of nauplii of Artemia fransiscana by ozonation. Progressive Fish Culturist 60, 149-151.

Tolomei, A., Burke, C., Crear, B., Carson, J. 2004. Bacterial decontamination of on-grown Artemia. Aquaculture, 232, 357-371.

Wester, P. W., Canton, J.H., Dormans, J.A.M.A. 1988. Pathological effects in freshwater fish Poecilia reticulata (guppy) and Oryzias latipes (medaka) following methyl bromide and sodium bromide exposure. Aquatic Toxicology 12, 323-343.

Wheatly, M.G. 1999. Calcium homeostasis in Crustacea: the evolving role of branchial, renal, digestive and hypodermal epithelia. Journal of Experimental Zoology 283, 620 640. 


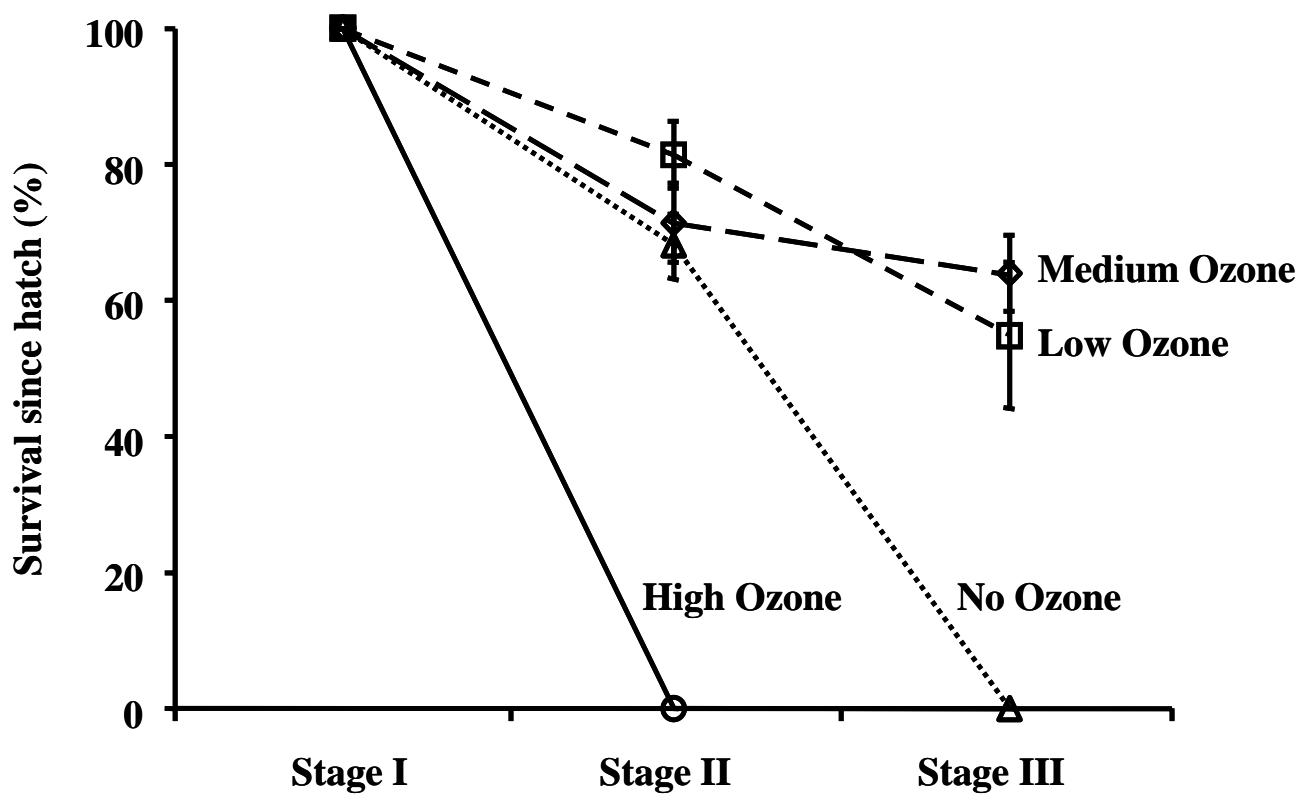

Fig. 1. The survival of phyllosoma larvae from hatch to Stage III (26 days after hatch) in seawater which was not ozonated (No Ozone), or ozonated at different levels (Low, Medium or High Ozone). 
(a)

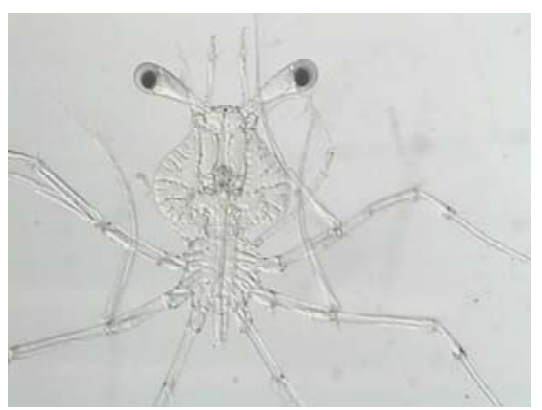

(b)

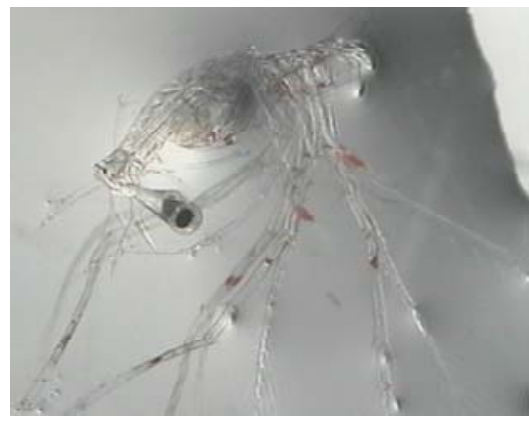

(c)

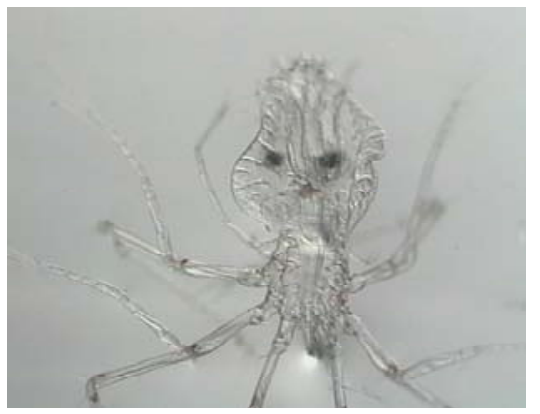

Fig. 2. (a) Normal Stage I phyllosoma. (b) Side view showing abnormalities in carapace shape at the attempted moult to Stage II due to high ozonation of seawater. Body has a curved appearance typical of the moult but remains fixed in this position. Note the invagination in the cephalic shield and the eyes curved beneath the plane of the cephalic shield. (c) Top view of same phyllosoma as in (b). 


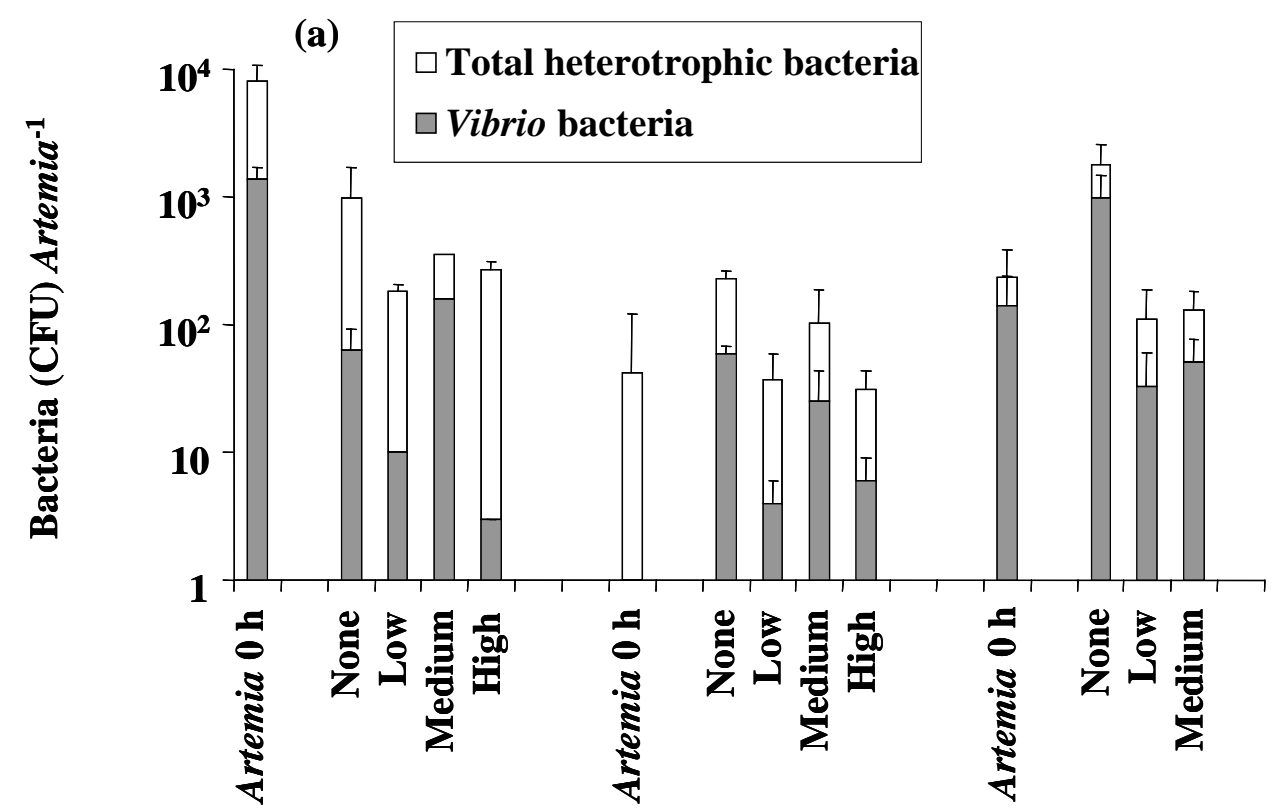

(b)

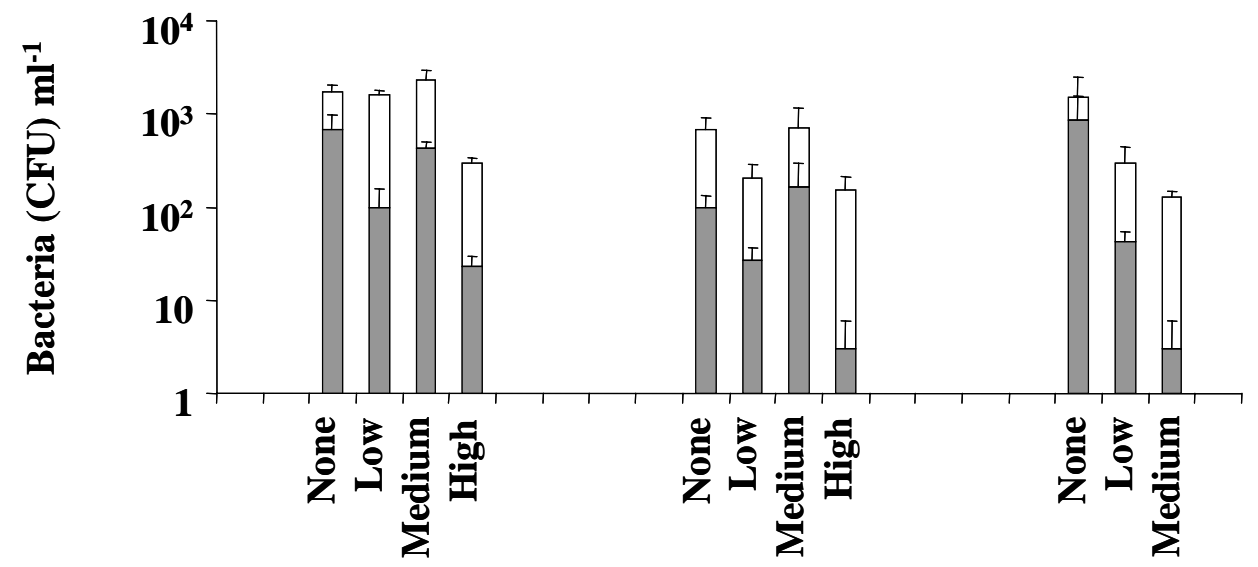

Day 5 Day $12 \quad$ Day 21

Fig. 3. Number of colony forming units (CFU, mean \pm sem) of heterotrophic bacteria and Vibrio bacteria at different levels of seawater ozonation on Days 5, 12 and 21 of larval culture for (a) Artemia before entry to phyllosoma culture tanks $(0 \mathrm{~h})$ and after $21 \mathrm{~h}$, and (b) water in culture tanks before Artemia flushed out. 

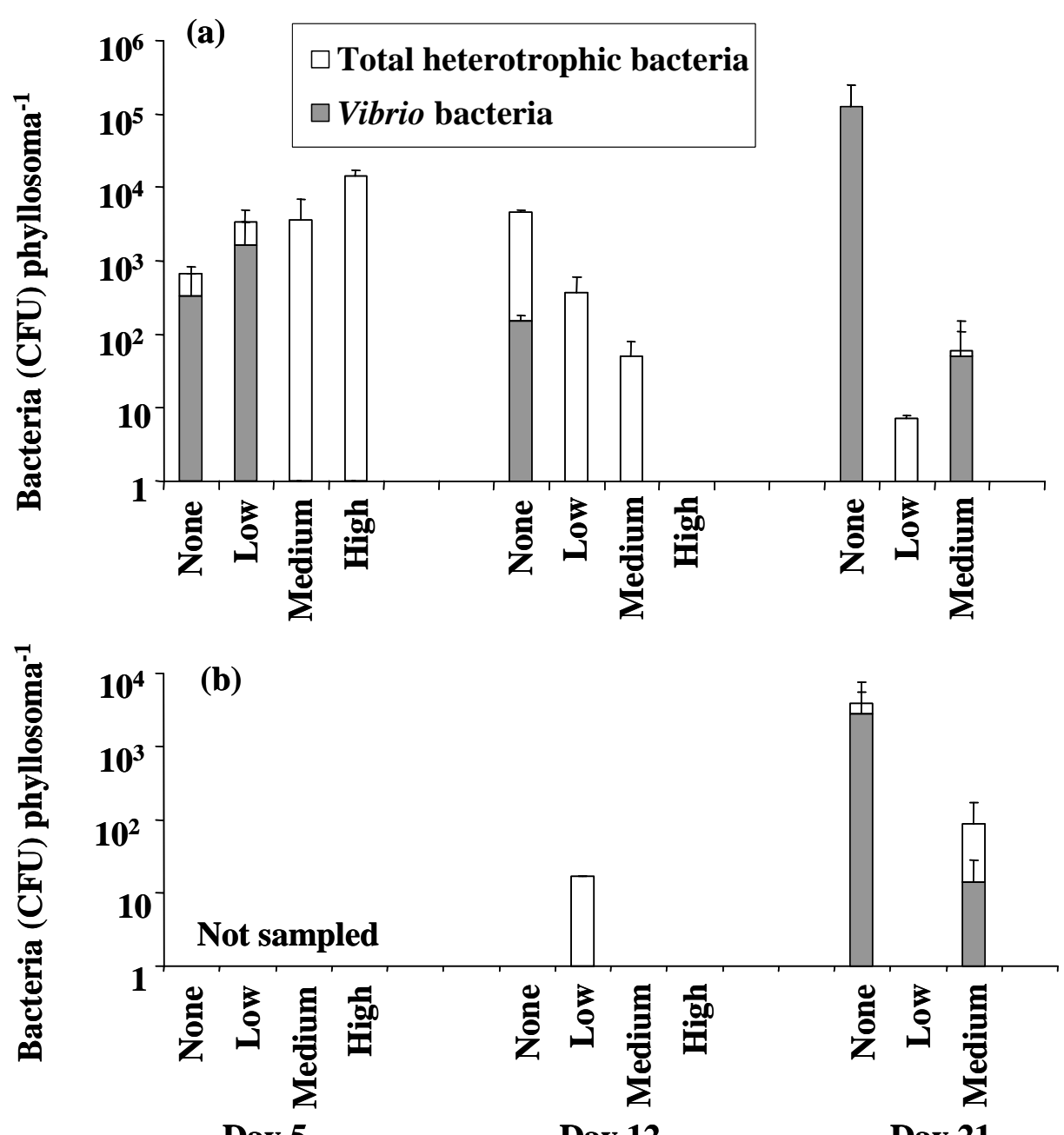

Day 5

Day 12

Day 21

Fig. 4. Number of colony forming units (CFU, mean \pm sem) of total heterotrophic bacteria and Vibrio bacteria in phyllosoma at different levels of seawater ozonation on Days 5 (mid Stage I), 12 (after moult to Stage II) and 21 (after moult to Stage III) after hatch (a) combined (internal plus external) bacteria, and (b) internal only bacteria. Note that no samples for phyllosoma internal only bacteria numbers were examined on Day 5. 


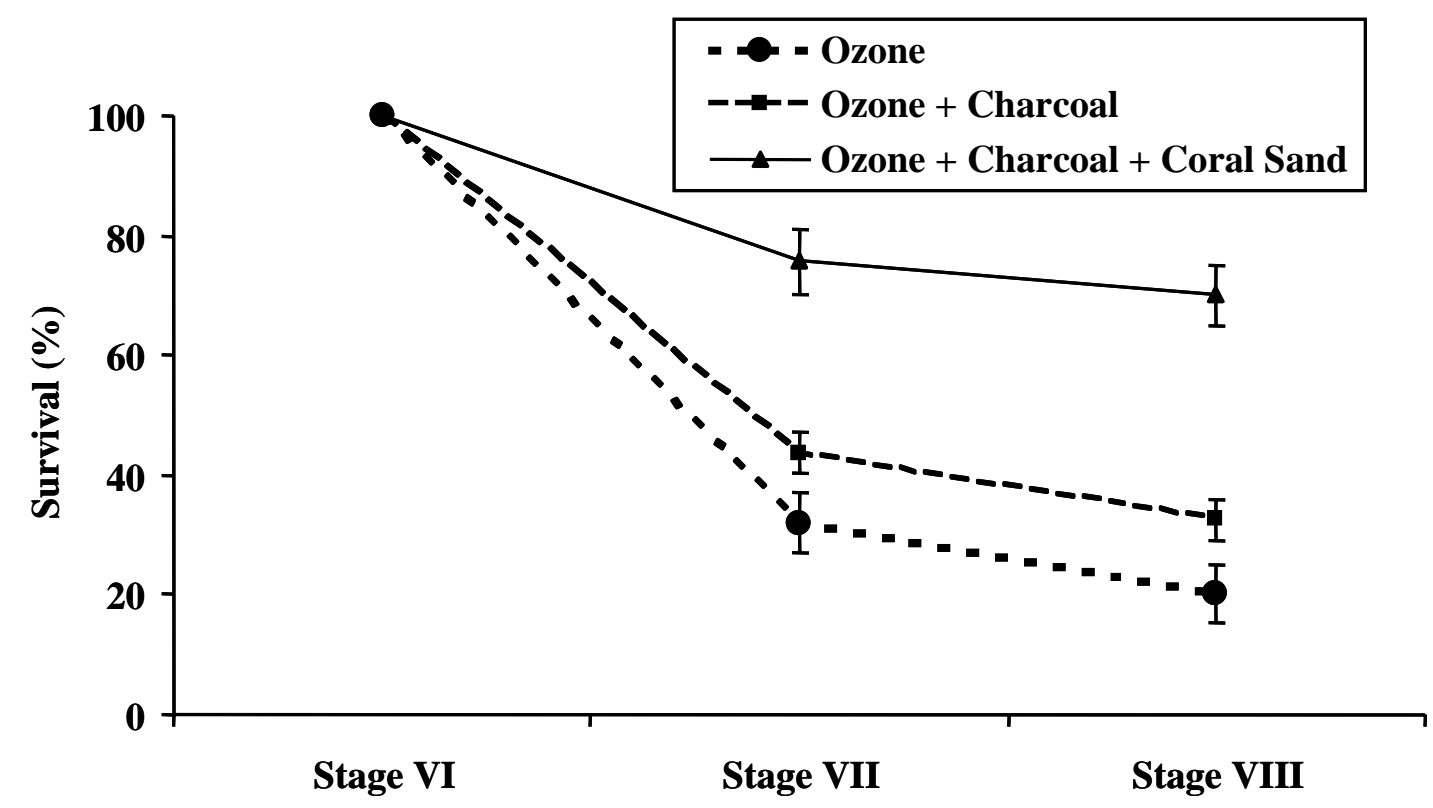

Fig. 5. Survival of phyllosoma cultured in ozonated water (ORP of 450-500 mV), ozonated water with charcoal filtration (ORP of 400-450 mV) or ozonated water with charcoal filtration and coral sand (ORP of 390-440 $\mathrm{mV}$ ozone). 


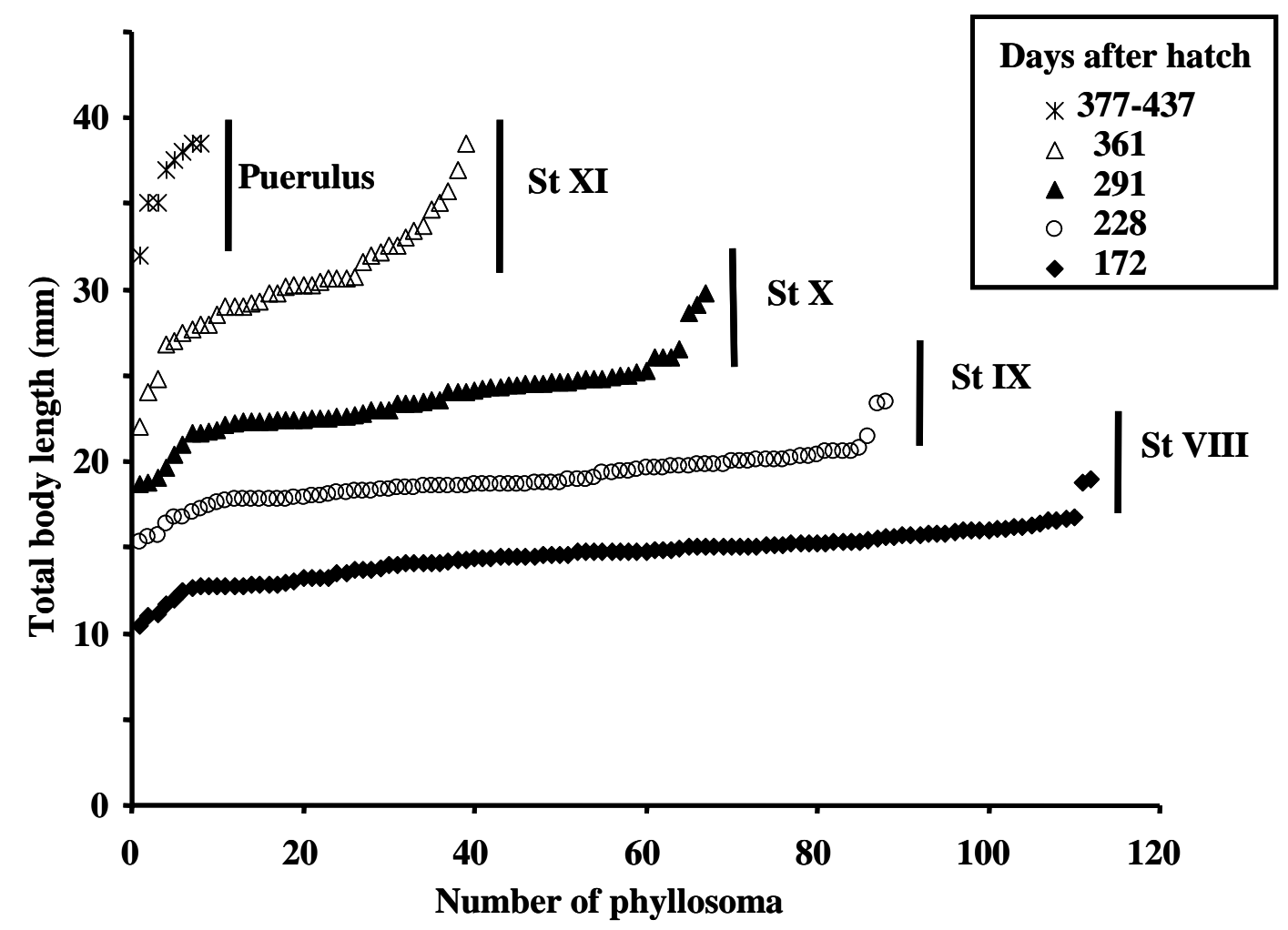

Fig. 6. The number of animals and their total body lengths when examined at phyllosoma Stages VIII to XI and at pueruli stage at different times after hatch. Vertical bars indicate range of total body lengths at each stage. 